\title{
Towards the Elimination of Mother to Child Transmission of Syphilis 2015- 2020: Practice and Progress in Zhejiang Province, Eastern China
}

\author{
Hong Wang \\ Department of Obstetrics, Women's Hospital, School of Medicine, Zhejiang University \\ Xia Ying \\ Department of Obstetrics, Women's Hospital, School of Medicine, Zhejiang University \\ Dan Lin \\ Department of Women's Health, Women's Hospital, School of Medicine, Zhejiang University \\ Muhuza Marie Parfaite Uwimana \\ School of Medicine, Zhejiang University \\ Xiaohui Zhang ( $\nabla$ zjfb_amy@zju.edu.cn) \\ Department of Women's Health, Women's Hospital, School of Medicine, Zhejiang University
}

\section{Research Article}

Keywords: Elimination of mother-to-child transmission (EMTCT), Adverse pregnancy outcomes (APOs), Screening, Treatment, Pregnant women Posted Date: August 4th, 2021

DOI: https://doi.org/10.21203/rs.3.rs-721592/v1

License: @) (7) This work is licensed under a Creative Commons Attribution 4.0 International License. Read Full License 


\section{Abstract \\ Objectives}

To estimate the progress towards elimination of mother-to-child transmission (EMTCT) of syphilis in Zhejiang province.

\section{Methods}

Data were obtained from Zhejiang provincial EMTCT network. Childbearing women infected with syphilis during 2015-2020 were recruited from. Joinpoint mode was used to analyze changing trends in syphilis screening, treatment and adverse pregnancy outcomes (APOs), presented as the annual percentage of change (APC). Multivariate logistic regression mode was used to investigate risk factors of APOs.

\section{Results}

Of 3,658,266 participants, an average maternal syphilis incidence was $0.38 \%$.From 2015 to 2020 , the coverage of syphilis screening in pregnancy ( $96.31-$ 99.24\%; $P<0.001)$ and coverage of antenatal health care (ANC) within 13 gestational weeks were increased $(55.27-77.82 \%$; $P=0.002)$. The coverage of maternal syphilis treatment $(88.30-98.25 \% ; P=0.001)$ and adequate treatment were also increased $(66.92-83.37 \% ; P=0.001) .0 v e r$ years, the $A P C$ was $19.30 \%(95 \% \mathrm{Cl}:-24.33 \sim-13.92, \mathrm{P}=0.001)$ in perinatal death,-26.55\% in congenital syphilis(95\%Cl:-38.75 -11.92, $\mathrm{P}=0.009)$ and $-14.67 \%$ in infant with abnormal signs (95\%Cl:-23.96 -4.24, $\mathrm{P}=0.019)$.In 2020, $11.58 \%$ of women had APOs. Women with syphilis infection during pregnancy aged (<20 years) or ( $\geq 35$ years), multiparous, with pregnancy complications increased (all $\mathrm{P}<0.05$ ).APOs risk increased in those with higher maternal RPR/TRUST titers, decreased when women had therapy, adequate therapy or early ANC, or aged in $21-34$ years (all $P<0.001)$.

\section{Conclusions}

Despite steady progress towards the goal of EMTCT in implementing universal screening and treatment, syphilis continuously affects a large number of pregnant women. Increasing vulnerable women, small proportions of inadequately treated and delay in early ANC should be noticed.

\section{Introduction}

The estimated worldwide prevalence of maternal syphilis in 2016 was $0.69 \%$ (95\% confidence interval: $0.57-0.81 \%) .{ }^{1}$ It has been estimated that $20-60 \%$ of adverse pregnancy outcomes (APOs) occur in syphilitic women, which would be worse in those unscreened, untreated, or inadequately treated. ${ }^{1-4}$ Maternal syphilis and associated negative impacts on infants are preventable. ${ }^{5}$ In 2007 , WHO advocated eliminating mother-to-child transmission of syphilis (EMTCT). ${ }^{6}$ With the improvement of syphilis screening and treatment in pregnant women, several countries such as Thailand and the Republic of Cuba have already achieved the EMTCT goals. ${ }^{7-8}$

In 2010 the Ministry of Health (MOH) of China made an announcement of a national Plan for Syphilis Control and Prevention (2010-2020) under the call of global EMTCT. ${ }^{9}$ In 2011, Guidelines for Prevention of Mother-to-Child Transmissions of HIV, Syphilis, and Hepatitis B virus (HBV) were integrated and implemented, which set an overall target of achieving $95 \%$ syphilis-screening coverage; $90 \%$ syphilis-screening coverage during pregnancy; $90 \%$ intervention coverage for infected pregnant women and their babies, and an incidence of congenital syphilis under 15 per 100,000 live births by $2020 .{ }^{9}$ In 2017 , the Chinese government launched a pilot project of EMTCT. Zhejiang was appointed as one of the three pilot provinces. According to our national surveillance data in 2013 and 2019, approximately half of pregnant women with syphilis were from Eastern China, and only half of them received their first antenatal health care (ANC),syphilis treatment coverage were still under $90 \%$,APOs were steady at $13 \% 14 \%$ over these years. ${ }^{11,12}$

The Zhejiang Province, located on the southeast coast of China, has a high gross domestic product (GDP) and large migrant population. ${ }^{13,14}$ Data from the Chinese Center for Disease Control and Prevention shows that syphilis incidence in Zhejiang Province ranked second in China in $2016 .{ }^{15}$ The burden of maternal syphilis is also critical in Zhejiang province, as 2013-2014 data shows that the average incidence was $0.3 \% .{ }^{16}$ The province has strengthened prevention mother to child transmission of syphilis project since 2015, performing routine maternal syphilis screening, treatment and surveillance at provincial level. Since inception of EMTCT program in 2017, we have taken series of measures to enhance the program towards WHO EMTCT goals, advocating social support, upholding human rights and reviewing MTCT failure cases etc. This study explored changing trends in maternal syphilis screening, treatment, APOs along with related risk factors since 2015. This analysis updated our previous research of 2013-2014. ${ }^{16}$ The findings would contribute to significant further guidance on EMTCT of syphilis in a high prevalence setting.

\section{Methods}

\section{Study design and data source}

The retrospective study obtained data from the Zhejiang provincial EMTCT information network, which is a mandatory case reporting system covering all health care institutions and delivery hospitals. In this study, we recruited pregnant women with syphilis who gave live births or stillbirths at 28 gestational weeks or above in 2015-2020. Study size was calculated by simple random sampling formula as follow. 
$n=\frac{Z_{\alpha, 2}^{2} p(1-p) N}{\delta^{2}(N-1)+Z_{\alpha, 2}^{2} p(1-p) N}$

P was defined as the overall rate of APOs (20\%).

$\delta=0.05$ (forgives errors), $a=0.05$ (examination standard).

The minimum study size of maternal syphilis was 246 . Therefore, the total number of maternal syphilis at provincial level is powerful enough to identify the APOs in the study.

\section{Introduction of EMTCT}

Integrated HIV, syphilis, and HBV screening is free for women during their first ANC in China. Regarding detection of maternal syphilis; syphilis rapid plasma regain (RPR), or toluidine red unheated serum test (TRUST), and Treponema Pallidum Hemagglutination Assay (TPHA) test or Treponema pallidum particle agglutination (TPPA) are used. If possible, laboratory confirmation of Treponema pallidum in clinical specimens by dark-field microscopy or reactive treponemal IgM antibody test is performed. Newborns meeting any of the following criteria are diagnosed with congenital syphilis: (1) Positive treponemal test and a value 4-fold higher titer of anontreponemal test than that of his/her mother's before delivery; (2) laboratory confirmation of T. pallidum in clinical specimens by dark-field microscopy; (3) reactive treponemal antibody test of IgM. These criteria are consistent with those mentioned in other literatures from China. ${ }^{11,12,16,17}$ Diagnosis of syphilis is done by professional clinicians; penicillin is offered for free as first line treatment and Ceftriaxone is the treatment choice for women who are allergic to Penicillin. Women infected with syphilis are followed up throughout pregnancy and postpartum by medical staff in women's and children's healthcare centers or hospitals at regional level. Infected women are entitled to safe delivery in hospital. Moreover, infants diagnosed with congenital syphilis and infants born to inadequately treated women are also offered free Penicillin treatment. Information on maternal sociodemographic characteristics, ANC service, syphilis screening, syphilis-related treatment, pregnancy outcomes, and birth information are collected through a web-based information system. Quality control is performed at the local level and provincial level medical staff, involving ANC service, laboratory quality, data collection, and associated therapy. Since 2017, we have initiated activities such as universal advocacy for anti-stigma, health education and social support and so on.

\section{Statistics}

SPSS 20.0(IBM SPSS Statistics for Windows, Version 27.0.Armonk, NY; IBM Corp), Stata version 13 (Stata Corp, College Station, TX, United States)and Joinpoint software (Version 4.7.0.0 - February 2019; Statistical Methodology and Applications Branch, Surveillance Research Program, National Cancer Institute) were used for statistical analysis. Descriptive estimates, including the number of syphilis screening per 100 pregnant women, the number of syphilis screening during pregnancy per 100 pregnant women, the number of maternal syphilis therapy per 100 syphilis-positive pregnant women, number and percentage by maternal social characteristics, and incidences of APOs, were calculated. The overall incidence of APOs was defined as births with any of the following low birth weight (LBW, birth weight under 2,500g), preterm birth (born before 37 gestational weeks), perinatal death (fetal death $\geq 28$ gestational weeks or new infant death within 7 days after birth), an infant with abnormal signs and congenital syphilis. Overall treatment indicates treatment during pregnancy or at delivery. Adequate treatment indicated two courses of Penicillin treatment (three injections per course, once a week) during pregnancy. RPR/TRUST results were divided into four groups according to maternal titres before deliver or the third trimester(titres $\geq 1: 32$, titres $=1: 16$, titres $=1: 8$ and titres $\leq 1: 4)$.

The chi-square test was used to analyze valuables distributions. Joinpoint Regression mode was used for changing trends analysis over the years to calculate annual percentage change and $95 \%$ confidence intervals (APC, 95\% $\mathrm{Cl}$ ). The risk of APOs was calculated using logistic regression mode with adjusted odds ratio presented together with $95 \%$ confidence intervals (OR and $95 \% \mathrm{Cl}$ ). All $\mathrm{P}$ value under 0.05 were regarded as statistically significant.

\section{Ethics approval and and data availability}

The study was performed in accordance with the Declaration of Helsinki and approved by Women's Hospital School of Medicine Zhejiang University ethics committee (No.20180180). The informed consent was not required since the data is secondary and available in Zhejiang provincial EMTCT information network, which has been mentioned as above. Data are available upon reasonable request.

\section{Results}

\section{Changes in syphilis screening and incidence in pregnant women}

During 2015-2020, the total number of pregnant women was 3,658,266. Of them, 3,655,371 had syphilis screening during pregnancy, and the rest had it at childbirth. The coverage of syphilis screening in pregnant women has remained at a high level and has improved gradually throughout the study period. Particularly, the coverage of syphilis screening in pregnancy increased significantly from $96.31 \%$ in 2015 to $99.24 \%$ in 2020 (APC = 0.60, 95\%Cl:0.48 0.71, P $<0.001$ ), and the coverage of ANC in first trimester in women increased from 55.27-77.82\% (APC = 6.71,95\%Cl:4.17 9.31, $P=0.002)$. The maternal syphilis incidences were stable over years(APC=2.08,95\%Cl:-2.79 7.19,P凶0.307), which was $0.44 \%$ in 2020 . Totally, 13,829 women were diagnosed with syphilis, giving an average incidence of $0.38 \%$. (Table 1 ) 
Table 1

Changes in coverage of syphilis screening, first antenatal health care visit and incidences of maternal syphilis during 2015-2020.

\begin{tabular}{|c|c|c|c|c|c|c|c|c|c|}
\hline Year & $\begin{array}{l}\text { Number } \\
\text { of } \\
\text { pregnant } \\
\text { women } \\
\text { (a) }\end{array}$ & $\begin{array}{l}\text { Number of } \\
\text { pregnant } \\
\text { women with } \\
\text { syphilis } \\
\text { screening } \\
\text { (b) }\end{array}$ & $\begin{array}{l}\text { Coverage of } \\
\text { syphilis } \\
\text { screening in } \\
\text { pregnant } \\
\text { women (b/a, \%) }\end{array}$ & $\begin{array}{l}\text { Number of } \\
\text { syphilis } \\
\text { screening in } \\
\text { women during } \\
\text { pregnancy } \\
\text { (c) }\end{array}$ & $\begin{array}{l}\text { Coverage of } \\
\text { maternal syphilis } \\
\text { screening during } \\
\text { pregnancy }(c / a, \%)\end{array}$ & $\begin{array}{l}\text { Number } \\
\text { of } \\
\text { women } \\
\text { with } \\
\text { syphilis } \\
\text { (d) }\end{array}$ & $\begin{array}{l}\text { Incidence } \\
\text { of } \\
\text { maternal } \\
\text { syphilis } \\
(\mathrm{d} / \mathrm{b}, \%)\end{array}$ & $\begin{array}{l}\text { Number of } \\
\text { women with } \\
\text { syphilis with } \\
\text { ANC in first } \\
\text { trimester } \\
\text { (e) }\end{array}$ & $\begin{array}{l}\text { Coverage } \\
\text { of } \\
\text { Women } \\
\text { with } \\
\text { syphilis } \\
\text { with ANC in } \\
\text { first } \\
\text { trimester } \\
(e / d, \%)\end{array}$ \\
\hline 2015 & 574,030 & 573,185 & 99.85 & 552,867 & 96.31 & 2,231 & 0.39 & 1,233 & 55.27 \\
\hline 2016 & 724,485 & 723,400 & 99.85 & 703,646 & 97.12 & 2,520 & 0.35 & 1,551 & 61.55 \\
\hline 2017 & 704,024 & 704,007 & 100.00 & 688,063 & 97.73 & 2,647 & 0.38 & 1,809 & 68.34 \\
\hline 2018 & 602,107 & 601,257 & 99.86 & 590,344 & 98.05 & 2,240 & 0.37 & 1,618 & 72.23 \\
\hline 2019 & 582,227 & 582,173 & 99.99 & 575,995 & 98.93 & 2,135 & 0.37 & 1,584 & 74.19 \\
\hline 2020 & 471,393 & 471,349 & 99.99 & 467,819 & 99.24 & 2,056 & 0.44 & 1,600 & 77.82 \\
\hline Total & $3,658,266$ & $3,655,371$ & 99.99 & $3,578,734$ & 97.83 & 13,829 & 0.38 & 9,395 & 67.94 \\
\hline
\end{tabular}

\section{Changes in the characteristics of women with syphilis}

During 2015-2020, the characteristics of women with syphilis significantly differed in some categories. There was an increase in women aged(<20 years) or ( $\geq 35$ years), with college or above education, multiparous, with pregnancy complications, and those who had relative lower RPR/TRUST serological titers ( $\leq$ $1: 4)$. However, the proportion of local residents and women getting married decreased. In 2020, the predominance were those aged $\geq 35$ years (22.23\%), with secondary education(73.78 \%),multipara (60.55\%),with pregnancy complications (19.60\%), married (89.98\%)and local residents (48.54\%).(Table 2) 
Table 2

Changes in maternal characteristics with syphilis.

\begin{tabular}{|c|c|c|c|c|c|c|c|c|c|c|}
\hline Variable & & 2015 & 2016 & 2017 & 2018 & 2019 & 2020 & total & $\chi^{2}$ & $P$ \\
\hline \multicolumn{11}{|l|}{ Maternal age } \\
\hline \multirow[t]{2}{*}{$<20$ years old } & $\mathrm{N}$ & 82 & 72 & 69 & 50 & 60 & 93 & 426 & 80.186 & $<0.001$ \\
\hline & $\%$ & 3.68 & 2.86 & 2.61 & 2.23 & 2.81 & 4.52 & 3.08 & & \\
\hline \multirow[t]{2}{*}{$\geq 35$ years old } & $\mathrm{N}$ & 343 & 417 & 552 & 438 & 448 & 457 & 2655 & & \\
\hline & $\%$ & 15.37 & 16.55 & 20.85 & 19.55 & 20.98 & 22.23 & 19.20 & & \\
\hline \multirow[t]{2}{*}{ Unemployed } & $\mathrm{N}$ & 1134 & 1288 & 1372 & 1107 & 1115 & 1043 & 7059 & 4.342 & 0.501 \\
\hline & $\%$ & 50.83 & 51.11 & 51.83 & 49.42 & 52.22 & 50.73 & 51.04 & & \\
\hline \multicolumn{11}{|l|}{ Education } \\
\hline \multirow[t]{2}{*}{ Primary } & $\mathrm{N}$ & 333 & 346 & 324 & 267 & 325 & 276 & 1871 & 43.626 & $<0.001$ \\
\hline & $\%$ & 14.93 & 13.73 & 12.24 & 11.92 & 15.22 & 13.42 & 13.53 & & \\
\hline \multirow[t]{2}{*}{ College } & $\mathrm{N}$ & 183 & 259 & 265 & 246 & 239 & 263 & 1455 & & \\
\hline & $\%$ & 8.20 & 10.28 & 10.01 & 10.98 & 11.19 & 12.79 & 10.52 & & \\
\hline \multirow[t]{2}{*}{ Middle } & $\mathrm{N}$ & 1715 & 1915 & 2058 & 1727 & 1571 & 1517 & 10503 & & \\
\hline & $\%$ & 76.87 & 75.99 & 77.75 & 77.10 & 73.58 & 73.78 & 75.95 & & \\
\hline \multirow[t]{2}{*}{ Multipara } & $\mathrm{N}$ & 1170 & 1438 & 1587 & 1322 & 1285 & 1245 & 6802 & $43.586^{*}$ & $<0.001$ \\
\hline & $\%$ & 52.44 & 57.06 & 59.95 & 59.02 & 60.19 & 60.55 & 57.78 & & \\
\hline \multirow[t]{2}{*}{ Marital status } & $\mathrm{N}$ & 2047 & 2321 & 2474 & 2089 & 1957 & 1850 & 12738 & 24.560 & $<0.001$ \\
\hline & $\%$ & 91.75 & 92.10 & 93.46 & 93.26 & 91.66 & 89.98 & 92.11 & & \\
\hline \multirow[t]{2}{*}{ Local residents } & $\mathrm{N}$ & 1222 & 1508 & 1503 & 1241 & 1053 & 998 & 7525 & $87.867^{\star}$ & $<0.001$ \\
\hline & $\%$ & 54.77 & 59.84 & 56.78 & 55.40 & 49.32 & 48.54 & 54.41 & & \\
\hline \multirow[t]{2}{*}{ Pregnancy complications } & $\mathrm{N}$ & 367 & 407 & 441 & 368 & 372 & 403 & 2358 & $12.262^{\star}$ & 0.031 \\
\hline & $\%$ & 16.45 & 16.15 & 16.66 & 16.43 & 17.42 & 19.60 & 17.05 & & \\
\hline \multirow[t]{2}{*}{ Maternal RPR/TRUST Serological titer $(\leq 1: 4)$} & $\mathrm{N}$ & 1803 & 2129 & 2225 & 1926 & 1852 & 1763 & 11698 & $37.024 *$ & $<0.001$ \\
\hline & $\%$ & 80.82 & 84.48 & 84.06 & 85.98 & 86.74 & 85.75 & 84.59 & & \\
\hline
\end{tabular}

* $\mathrm{P}$ for trend

\section{Changes in syphilis treatment}

During 2015 to 2020, we observed a dramatic change in the overall treatment coverage, increasing from 88.30-98.25\% (APC = 2.37, 95\% Cl: 1.63 3.12, $\mathrm{P}=$ 0.001). Also, the coverage of adequate treatment gradually increased from $66.92-83.37 \%$ (APC $=4.84,95 \% \mathrm{Cl}$ : $3.49 \sim 6.21, \mathrm{P}=0.001)$.It is worth mentioning that the gap between natives and migrants was narrowed (all $\mathrm{P}<0.001)$. (Table 3 ) 
Table 3

Changes in maternal syphilis treatment between women living in Zhejiang or coming from other provinces.

\begin{tabular}{|c|c|c|c|c|c|c|c|c|c|c|c|c|c|c|}
\hline \multirow[t]{2}{*}{ Year } & \multirow{2}{*}{$\begin{array}{l}\text { Number } \\
\text { of } \\
\text { women } \\
\text { with } \\
\text { syphilis }\end{array}$} & \multicolumn{2}{|l|}{$\begin{array}{l}\text { Overall } \\
\text { treatment }\end{array}$} & \multicolumn{2}{|c|}{$\begin{array}{l}\text { Adequate } \\
\text { treatment }\end{array}$} & \multirow[t]{2}{*}{ Zhejiang } & \multicolumn{2}{|l|}{$\begin{array}{l}\text { Overall } \\
\text { treatment }\end{array}$} & \multicolumn{2}{|c|}{$\begin{array}{l}\text { Adequate } \\
\text { treatment }\end{array}$} & \multirow[t]{2}{*}{$\begin{array}{l}\text { Other } \\
\text { provinces }\end{array}$} & $\begin{array}{l}\text { Overall } \\
\text { treatment }\end{array}$ & \multicolumn{2}{|c|}{$\begin{array}{l}\text { Adequate } \\
\text { treatment }\end{array}$} \\
\hline & & Number & $\begin{array}{l}\text { Rate } \\
\text { (\%) }\end{array}$ & Number & $\begin{array}{l}\text { Rate } \\
(\%)\end{array}$ & & Number & $\begin{array}{l}\text { Rate } \\
(\%)\end{array}$ & Number & $\begin{array}{l}\text { Rate } \\
(\%)\end{array}$ & & Number & $\begin{array}{l}\text { Rate } \\
(\%)\end{array}$ & Numb \\
\hline 2015 & 2231 & 1970 & 88.30 & 1493 & 66.92 & 1222 & 1107 & 90.59 & 892 & 73.00 & 1009 & 863 & 85.53 & 601 \\
\hline 2016 & 2520 & 2261 & 89.72 & 1715 & 68.06 & 1509 & 1366 & 90.52 & 1084 & 71.84 & 1011 & 895 & 88.53 & 631 \\
\hline 2017 & 2647 & 2467 & 93.20 & 1932 & 72.99 & 1503 & 1408 & 93.68 & 1124 & 74.78 & 1144 & 1059 & 92.57 & 808 \\
\hline 2018 & 2240 & 2154 & 96.16 & 1762 & 78.66 & 1241 & 1194 & 96.21 & 995 & 80.18 & 999 & 960 & 96.10 & 767 \\
\hline 2019 & 2135 & 2084 & 97.61 & 1702 & 79.72 & 1053 & 1026 & 97.44 & 864 & 82.05 & 1082 & 1058 & 97.78 & 838 \\
\hline 2020 & 2056 & 2020 & 98.25 & 1714 & 83.37 & 997 & 984 & 98.70 & 837 & 83.95 & 1059 & 1036 & 97.83 & 877 \\
\hline $\begin{array}{l}\text { APC } \\
(95 \% \mathrm{Cl})\end{array}$ & & \multicolumn{2}{|c|}{$2.37(1.63,3.12)$} & \multicolumn{3}{|c|}{$4.84(3.49,6.21)$} & \multicolumn{2}{|c|}{$1.99(1.33,2.65)$} & \multicolumn{2}{|c|}{$3.46(1.87,5.08)$} & & $\begin{array}{l}2.88(1.73, \\
4.04)\end{array}$ & \multicolumn{2}{|c|}{$6.89(4.63, '$} \\
\hline$P$ & & $<0.001$ & & $<0.001$ & & & $<0.001$ & & $<0.001$ & & & $<0.001$ & & 001 \\
\hline
\end{tabular}

Changes in pregnancy outcomes and risk factors

Over the years, there have been no significant decrease in the overall incidence of APOs (from 11.56\%to 10.02\%); however the incidences of perinatal death, congenital syphilis and infant with abnormal signs decreased significantly. In 2020, all of the above mentioned incidences decreased to the lowest level, which were $6.14 \%, 2.36 \%$ and $0.57 \%$, respectively. The APC of perinatal death was $-19.30 \%(95 \% \mathrm{Cl}:-24.33 \sim-13.92$, $\mathrm{P}=0.001)$, and that of congenital syphilis was - 26.55\% (95\%Cl:-38.75 -11.92, P = 0.009). The APC of children with abnormal physical signs was $-14.67 \%(95 \% \mathrm{Cl}:-23.96$ to $-4.24, \mathrm{P}=0.019)$. (Table 4)

Table 4

Changes of APOs incidences by categories during 2015-2020.

\begin{tabular}{|c|c|c|c|c|c|c|c|c|c|c|c|}
\hline \multirow[t]{2}{*}{ Year } & \multirow[t]{2}{*}{ Number of birth } & \multicolumn{2}{|c|}{ Overall APOs } & \multicolumn{2}{|c|}{ LBW/preterm birth } & \multicolumn{2}{|c|}{ Perinatal death } & \multicolumn{2}{|c|}{ Congenital syphilis } & \multicolumn{2}{|c|}{ Abnormal sign } \\
\hline & & $\mathbf{n}$ & $\%$ & $\mathrm{n}$ & $\%$ & $\mathbf{n}$ & $\%$ & $\mathrm{n}$ & $\%$ & $\mathrm{n}$ & $\%$ \\
\hline 2015 & 2246 & 259 & 11.53 & 251 & 11.18 & 42 & 18.70 & 18 & 8.01 & 28 & 1.25 \\
\hline 2016 & 2539 & 288 & 11.34 & 261 & 10.28 & 36 & 14.18 & 23 & 9.06 & 37 & 1.46 \\
\hline 2017 & 2689 & 282 & 10.49 & 251 & 9.33 & 29 & 10.78 & 15 & 5.58 & 33 & 1.23 \\
\hline 2018 & 2273 & 258 & 11.35 & 243 & 10.69 & 25 & 11.00 & 7 & 3.08 & 21 & 0.92 \\
\hline 2019 & 2196 & 246 & 11.20 & 241 & 10.97 & 16 & 7.29 & 5 & 2.28 & 18 & 0.82 \\
\hline 2020 & 2116 & 245 & 11.58 & 205 & 9.69 & 13 & 6.14 & 5 & 2.36 & 12 & 0.57 \\
\hline \multicolumn{2}{|c|}{ APC(95\% Cl) } & \multicolumn{2}{|c|}{$0.16(-2.57,2.97)$} & \multicolumn{2}{|c|}{$-1.00(-6.02,4.28)$} & \multicolumn{2}{|c|}{$-19.30(-24.33,-13.92)$} & \multicolumn{2}{|c|}{$-26.55(-38.75,-11.92)$} & \multicolumn{2}{|c|}{$-14.67(-23.96,-4.24)$} \\
\hline \multicolumn{2}{|l|}{$P$} & \multicolumn{2}{|c|}{0.877} & \multicolumn{2}{|c|}{0.618} & \multicolumn{2}{|c|}{0.001} & \multicolumn{2}{|c|}{0.009} & \multicolumn{2}{|c|}{0.019} \\
\hline
\end{tabular}

The risk of APOs for untreated or incompletely treated, below 20 years and above 34 years, late in ANC or unmarried decreased when compared with those who were treated or adequately treated, aged between 21 and 34 years, had early ANC. It was worth noting that risk of APOs increased with increasing maternal RPR/TRUST titers.(Table 5, Fig. 1) 
Table 5

Predictors for adverse pregnancy outcomes by multiple logistic mode

\begin{tabular}{|c|c|c|c|c|}
\hline Variable & B & Wald & $\mathbf{P}$ & $\mathrm{OR}_{\mathrm{adj},}, 95 \% \mathrm{Cl}$ \\
\hline Treatment & -0.35 & 15.33 & $<0.001$ & $0.71(0.59 \sim 0.84)$ \\
\hline Complete-treatment & -0.50 & 60.98 & $<0.001$ & $0.61(0.54 \sim 0.69)$ \\
\hline \multicolumn{5}{|l|}{$\geq 35$ years old } \\
\hline$<20$ years old & -0.08 & 0.42 & 0.516 & $0.92(0.73 \sim 1.18)$ \\
\hline $21 \otimes 34$ years old & -0.29 & 20.06 & $<0.001$ & $0.75(0.66 \sim 0.85)$ \\
\hline \multicolumn{5}{|l|}{ College } \\
\hline Middle & 0.22 & 3.76 & 0.052 & $1.24(1.00 \sim 1.55)$ \\
\hline $\begin{array}{l}\text { Primary or } \\
\text { under primary }\end{array}$ & 0.13 & 1.84 & 0.175 & $1.14(0.95 \sim 1.37)$ \\
\hline Multipara & -0.05 & 0.777 & 0.378 & $0.95(0.86 \sim 1.06)$ \\
\hline Adverse pregnancy history & 0.11 & 2.69 & 0.101 & $1.11(0.98 \sim 1.26)$ \\
\hline $\begin{array}{l}\text { RPR/TRUST } \\
\leq 1: 4\end{array}$ & & 101.33 & $<0.001$ & \\
\hline$\geq 1: 32$ & 0.83 & 81.68 & $<0.001$ & $2.30(1.92 \sim 2.75)$ \\
\hline 1:16 & 0.58 & 28.77 & $<0.001$ & $1.78(1.44 \sim 2.19)$ \\
\hline $1: 8$ & 0.19 & 3.58 & 0.058 & $1.21(0.99 \sim 1.48)$ \\
\hline \multicolumn{5}{|l|}{ First ANC } \\
\hline Third trimester & & 18.91 & $<0.001$ & \\
\hline First trimester & -0.33 & 16.79 & $<0.001$ & $0.72(0.61 \sim 0.84)$ \\
\hline Second trimester & -0.35 & 15.70 & $<0.001$ & $0.70(0.59 \sim 0.84)$ \\
\hline Married & -0.12 & 6.58 & 0.010 & $0.89(0.81 \sim 0.97)$ \\
\hline Employment & 0.04 & 0.21 & 0.648 & $1.04(0.88 \sim 1.23)$ \\
\hline
\end{tabular}

\section{Discussion}

This study indicates improvement in syphilis screening and treatment in pregnant women, especially the narrowed gap between local residents and migrants. In 2020, vast majority of pregnant women were screened for syphilis in their ANC, over $95 \%$ maternal syphilis received therapy, congenital syphilis (CS) incidence was at a low level, meeting the global goals of EMTCT ${ }^{4}$.Between 2012 and 2016, and coverage of syphilis testing increased from 59-66\%, and treatment increased from $74-78 \%$ all over the world ${ }^{1}$. At Chinese national level, treatment coverage reached $89.52 \%$ in 2019 , and remarkable achievements on EMTCT of syphilis have also been reported at regional level at home and abroad ${ }^{11,17-21}$. Findings in our study reflected persistent progress towards EMTCT over the past years as a pilot area. EMTCT program were enhanced and financed by both Chinese and Zhejiang local government, promoting accessibility and equality of services. EMTCT has been integrated with current basic ANC services for women in Zhejiang, an increase in coverage of early ANC as well as sustainable provision of Penicillin also contributed to the improvement.

Maternal syphilis incidence has remained at high level throughout the study period in Zhejiang. In 2020 , it reached $0.44 \%$, which is higher than the Netherlands (0.06-0.08\%), lower than Africa (2.7\%), Latin American (1.1\%) and Beijing(China) (1.4\%o), however similar to Shanghai (0.20-0.38\%)(China). ${ }^{19,21-28}$ The epidemic of maternal syphilis in this study is slightly expanded compared to the previous study of Zhejiang in $2013-2014 .{ }^{16}$ As the global maternal syphilis remained stable in most area, the growth of syphilis in pregnant women in Zhejiang should be given serious consideration. ${ }^{1}$ On the one hand, it should be possible due to changes in sexual network structure and increase in screening. On the other hand, growth in multipara with syphilis would also result in increase of maternal syphilis prevalence.

Early ANC is critical for timely intervention and adequate treatment. During 2015 to 2020, ANC in first trimester increased by $6.71 \%$ annually. Consequently, the most increase was found to be adequate therapy among women, rising by $4.84 \%$ per year, and $6.89 \%$ increase in migrants. The findings prove the effective because we gave case reviews on those women delayed early ANC, inadequate treatment or vertical transmission since 2017.Barriers to access early ANC or effective EMTCT services were comparable to other studies, such as poor awareness of ANC in pregnant women, limited EMTCT knowledge in healthcare 
providers, vulnerabilities in laboratory facilities as reported elsewhere. ${ }^{22,24-25}$ One step of screening and treatment package should been strengthened for improvement of follow up as widely suggested. . $^{23-24}$

We evaluated the characteristics of women with syphilis in order to develop target interventions. The proportion of women with advanced age( $\geq 35 y e a r s)$ increased greatly, exceeding $20 \%$. The rapid development of social-economy, work and lifestyle pressure ,might force women to put off giving birth, particularly since the new birth policy changes in China. ${ }^{29-30}$ Similarly,reports indicated that women with syphilis infection were more likely to be illiterate, migrants and multiparous at regional and national level. ${ }^{11,17}$ Furthermore, a rise in pregnancy complications proportion in women with syphilis might be the consequence of increasing number of women with advanced age and higher parity. This point highlighted the need for the potential improved risk management for APOs.

The average incidence of APOs at our national level was 13.82\% in 2016-2019, reflecting fetal loss or stillbirth, as well as abnormal infant parameters. In Guangzhou, this figure was $27.3 \%$ during 2011-2018, including ectopic pregnancy, spontaneous abortion, stillbirth, prematurity or LBW, a live infant birth weight of less than the 10th percentile by gestational age and sex, infant death and CS. ${ }^{31}$ Therefore, differences in inclusion and exclusion criteria in different studies while comparing the overall occurrences of APOs should be given consideration. Exclusion of early fetal loss in our study resulted in decreased incidence of APOs for this reason the incidence of APOs might be underestimated. LBW/preterm birth was the most common subtypes of APOs, which was shown in previous studies. ${ }^{4,11,31}$ No significant decline in LBW/preterm birth was possible for the composite negative effect from increasing maternal age and pregnancy complications. The obvious reduction of APOs categories were predominantly in CS, abnormal signs and perinatal death. Our hypothesis indicates increasing coverage and effectiveness of testing, early ANC, and treatment. Women with treatment, especially adequate treatment, early ANC and appropriate maternal age were less likely to experience APOs. APOs risk increased with maternal RPR/TRUST titers, which was significantly severe among women with atiter of $\geq 1: 32$ at delivery or third trimester. The above evidences have been widely reported, and persisting low nontreponemal titers ( $<1: 8)$ is frequently suggested. $2-5,11,31$

This study has several limitations. Firstly, we focused on selected APOs. Missing information on early fetal loss and abortion could lead to some selection bias to the comprehensive understanding of APOs associated with syphilis. Secondly, some risk factors, such as the mother's stage of syphilis infection, gestational age at syphilis status, mode of delivery, sexual partner's infection status and congenital birth defects, were not considered. ${ }^{5,11,26}$ Lastly, Zhejiang is a province with rapid economic growth and with qualified healthcare system. The lessons from Zhejiang's experiences need to be considered cautiously by other less developed regions.

\section{Conclusions}

This study included a substantial number of pregnant women, thus providing a powerful and effective detection of maternal syphilis and associated APOs. In summary, expanding the coverage of syphilis screening, early ANC, and adequate treatment will be the most effective way to improve pregnancy outcomes and promote the health condition of infants born to maternal syphilis, even in a high endemic region.

\section{Declarations}

\section{Acknowledgments}

We thank all women and children centers/hospitals in Zhejiang Province for EMTCT, also thank LetPub (www.letpub.com) for its linguistic assistance during the preparation of this manuscript.

\section{Contributors}

WH and ZXH conceived the analysis. WH, YX, ZXH designed the study and drafted the manuscript. YX, LD, Muhuza Marie Parfaite Uwimana participated in data collection and statistics analysis. ZXH is responsible for the project. All authors contributed to data interpretation, revision and approval of the final manuscript.

\section{Funding}

This work was supported by Zhejiang Provincial Science and Technology Department [2019C35028].The study was also funded by UNICEF China, 501 Health, Nutrition and Wash-MCH; Increased evidence and policymakers' capacity Piloting, Elimination of mother to child transmission of HIV, syphilis and HBV (EMTCT).

\section{Data availability statement}

Data are available upon reasonable request. The Study group will review proposals. Please contact Corresponding author, Dr Xiaohui Zhang (zjfb_amy@zju.edu.cn).

\section{Ethics approval and consent to participants}

The study was performed in accordance with the Declaration of Helsinki and approved by Women's Hospital School of Medicine Zhejiang University ethics committee (No.20180180). The informed consent was not required since the data is secondary and available in Zhejiang provincial EMTCT information network, which has been mentioned as above. All methods were performed in accordance with the relevant guidelines and regulations.

\section{Consent for publication}


Not applicable.

\section{Competing interests}

The authors have no conflict of interest to declare.

\section{References}

1. Korenromp EL, Rowley J, Alonso M, Mello MB, Wijesooriya NS, Mahiané SG, et al. Global burden of maternal and congenital syphilis and associated adverse birth outcomes-Estimates for 2016 and progress since 2012. PLoS One 2019;14:e0211720.

2. Gomez GB, Kamb ML, Newman LM, Mark J, Broutet N, Hawkes SJ. Untreated maternal syphilis and adverse outcomes of pregnancy: a systematic review and meta-analysis. Bull World Health Organ 2013;91:217-26.

3. Qin JB, Feng TJ, Yang TB, Hong FC, Lan LN, Zhang CL. Risk Factors for Congenital Syphilis and Adverse Pregnancy Outcomes in Offspring of Women With Syphilis in Shenzhen, China: A Prospective Nested Case- Control Study. Sex Transm Dis 2014;41:13-23.

4. Newman L, Kamb M, Hawkes S, Gomez G, Say L, Seuc A, Broutet N. Global estimates of syphilis in pregnancy and associated adverse outcomes: analysis of multinational antenatal surveillance data. PLoS Med 2013;10:e1001396.

5. Rac MW, Revell PA, Eppes CS. Syphilis during pregnancy: a preventable threat to maternal-fetal health. Am J Obstet Gynecol 2017;216:352-63.

6. World Health Organization. The Global elimination of congenital syphilis: rationale and strategy for action. Geneva: World Health Organization, 2007. http://www.who.int/reproductivehealth/publications/rtis/9789241595858/en/index.html (accessed 12 ${ }^{\text {th }}$ December 2020).

7. World Health Organization. WHO validates elimination of mother-to-child transmission of HIV and syphilis in Cuba. Saudi Med J 2015;36:1018-9.

8. Sidibé M, Singh PK. Thailand eliminates mother-to-child transmission of HIV and syphilis. Lancet 2016;387:2488-9.

9. National Health Commission of the People's Repulic of China. 2010-2020 Plan for Syphilis Control and Prevention [2010] No.52. http://www.nhc.gov.cn/bgt/s10788/201006/910725223b02457ab0f81cd1773779fc.shtml (accessed 12 ${ }^{\text {th }}$ December 2020).

10. Wu D, Hawkes S, Buse K. Prevention of mother-to-child transmission of syphilis and HIV in China: What drives political prioritization and what can this tell us about promoting dual elimination? Int J Gynaecol Obstet 2015;130(Suppl 1):S32-6.

11. Li Z, Wang Q, Qiao Y, Wang X, Jin X, Wang A. Incidence and associated predictors of adverse pregnancy outcomes of maternal syphilis in China, 2016-19: a Cox regression analysis. BJOG 2020; https://doi.org/10.1111/1471-0528.16554.

12. Dou L, Wang X, Wang F, Wang Q, Qiao YP, Su M et al. Epidemic Profile of Maternal Syphilis in China in 2013. Biomed Res Int 2016;2016:9194805.

13. Statista. Per capita gross domestic product (GDP) in China in 2019, by province or region.https://www.statista.com/statistics/1093666/china-per-capitagross-domestic-product-gdp-by-province/ (accessed $12^{\text {th }}$ December 2020).

14. Unicef. Figure 1.19 Migrant population, by province, 2015. https://www.unicef.cn/en/figure-119-migrant-population-province-2015 (accessed $12^{\text {th }}$ December 2020).

15. Chinese Center for Disease Control and Prevention. Syphilis. http://www.phsciencedata.cn/Share/ky_sjml.jsp?id=3b00c675-b975-4505-a48fe086519c7b49 (accessed 12 ${ }^{\text {th }}$ December 2020).

16. Zhang XH, Xu J, Chen DQ, Guo LF, Qiu LQ. Effectiveness of treatment to improve pregnancy outcomes among women with syphilis in Zhejiang Province, China. Sex Transm Infect 2016;92:537-41.

17. Du L, Li Y, Jin H, Huang C, Gu YB, Zhu LP, et al. Prevent Mother-to-Child Transmission (PMTCT) Programs and Enhancement of Maternal Healthcare Infrastructure to Improve Early Detection of Maternal Syphilis in Shanghai, China. Int J Environ Res Public Health. 2019 Mar 20;16(6):1002.

18. Wu YL, Gao J, Qin JB, He J, Wang AH, Wang H, et al. Mother-to-child transmission prevention of human immunodeficiency virus, syphilis and hepatitis B virus. Women Birth. 2019 Dec;32(6):570-578.

19. Li Y, Zhu LP, Du L, Qu LX, Jiang WL, Xu B, et al. Effects on preventing mother-to-child transmission of syphilis and associated adverse pregnant outcomes: a longitudinal study from 2001 to 2015 in Shanghai, China. BMC Infect Dis 2017;17:626.

20. Trivedi S, Taylor M, kamb ML, Chou D. Evaluating coverage of maternal syphilis screening and treatment within antenatal care to guide service improvements for prevention of congenital syphilis in Countdown 2030 Countries. J Glob Health 2020;10:010504.

21. Cha S, Malik T, Abara WE, DeSimone MS, Schumann B, Mallada E, et al. Screening for Syphilis and Other Sexually Transmitted Infections in Pregnant Women - Guam, 2014. MMWR Morb Mortal Wkly Rep 2017;66:644-8.

22. Dassah ET, Adu-Sarkodie Y, Mayaud P. Rollout of rapid point of care tests for antenatal syphilis screening in Ghana: healthcare provider perspectives and experiences. BMC Health Serv Res 2018;18:130.

23. Perez F, Mayaud P. One step in the right direction: improving syphilis screening and treatment in pregnant women in Africa. Lancet Glob Health 2019;7:e550-1.

24. Visser M, van der Ploeg CPB, Smit C, Hukkelhoven CWPM, Abbink F, van Benthem BHB, et al. Evaluating progress towards triple elimination of mother-tochild transmission of HIV, syphilis and hepatitis B in the Netherlands. BMC Public Health 2019;19:353.

25. Trope LA, Wijesooriya NS, Broutet N, Temmerman M, Newman L. Reaching beyond pregnant women to eliminate mother-to-child transmission of syphilis in Africa. Expert Rev Anti Infect Ther 2014;12:705-14.

26. Arnesen L, Martínez G, Mainero L,Serruya S, Durán P. Gestational syphilis and stillbirth in Latin America and the Caribbean. Int J Gynaecol Obstet 2015;128:241-5.

Page 9/10 
27. Zhang X, Yu Y, Yang H, Xu HY, Vermund SH, Liu KB. Surveillance of Maternal Syphilis in China: Pregnancy Outcomes and Determinants of Congenital Syphilis. Med Sci Monit, 2018; 24: 7727-7735.

28. Wijesooriya NS, Rochat RW, Kamb ML, Turlapati P, Temmerman M, Broutet N, et al. Global burden of maternal and congenital syphilis in 2008 and 2012 : a health systems modelling study. Lancet Glob Health 2016;4:e525-33.

29. Aoyama K, Pinto R, Ray JG,Hill AD, Scales DC, Lapinsky SE, et al. Association of Maternal Age With Severe Maternal Morbidity and Mortality in Canada. JAMA Netw Open 2019;2:e199875.

30. Zhang $\mathrm{XH}$, Chen LJ, Wang XM, Wang XY, Jia MH, Ni SL, et al. Changes in maternal age and prevalence of congenital anomalies during the enactment of China's universal two-child policy (2013-2017) in Zhejiang Province, China: An observational study. PLoS Med 2020;17:e1003047.

31. Hu F, Guo SJ, Lu JJ, Zhu S, Hua NX, Song YY, et al. The Effect of Different Treatment Regimens and Multiple Risk Factors on Adverse Pregnancy Outcomes among Syphilis-Seropositive Women in Guangzhou: A Retrospective Cohort Study. Biomed Res Int 2020; $2020: 7626274$.

\section{Figures}

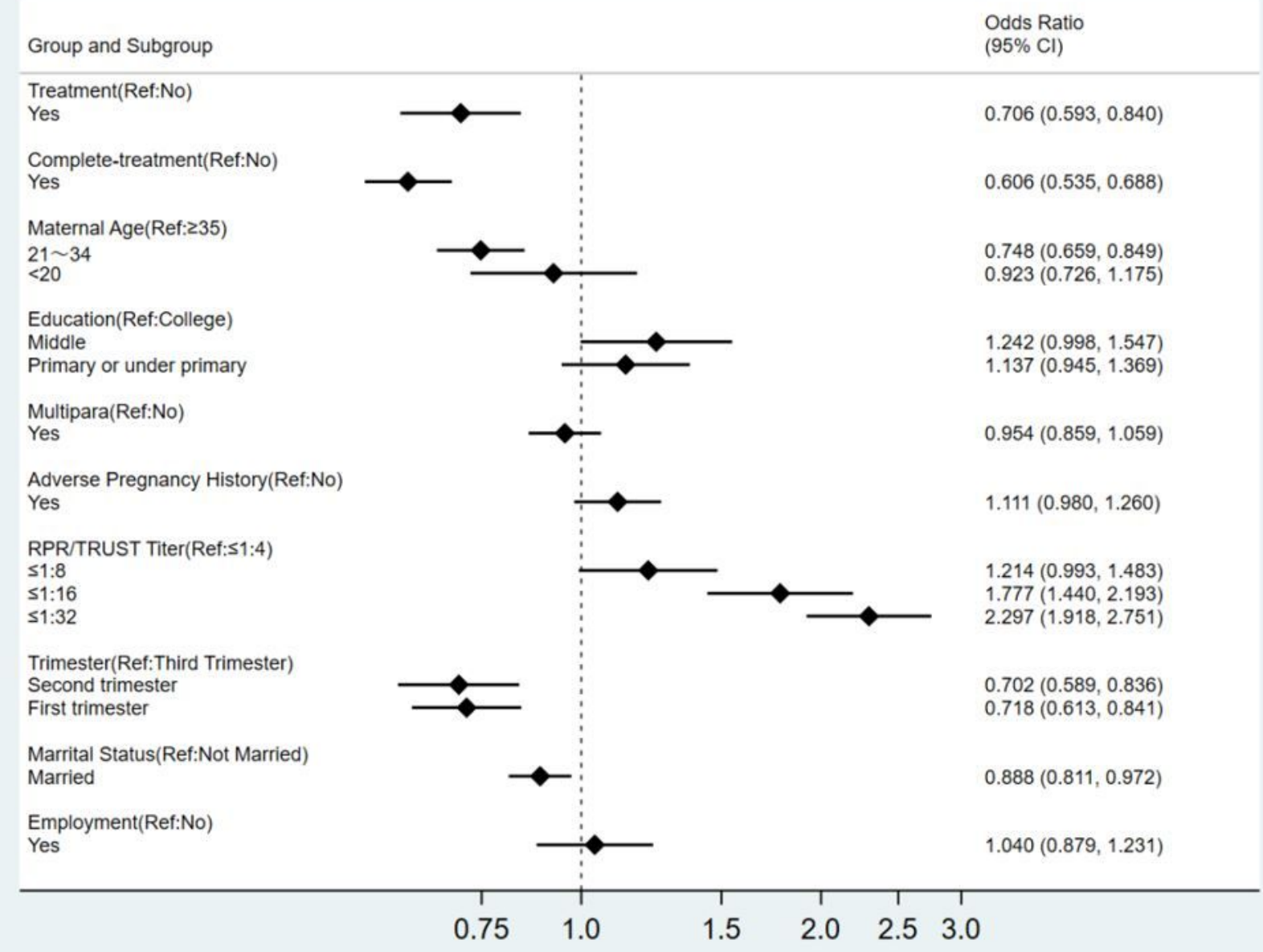

\section{Figure 1}

Predictors for adverse pregnancy outcomesby multiple logistic mode 